\title{
The Unique Gold Nanorods Embedded Active Layer Enabling Strong Plasmonic Effect to Improve the Performance of Polymer Photovoltaic Devices
}

\author{
Chunyu Liu, ${ }^{\mathrm{a}}$ Chaoyang Zhao, ${ }^{\mathrm{b}}$ Xulin Zhang, ${ }^{\mathrm{a}}$ Wenbin Guo, ${ }^{*}$ a Kun Liu, * ${ }^{\mathrm{b}}$ Shengping Ruan ${ }^{\mathrm{a}}$ \\ ${ }^{a}$ State Key Laboratory on Integrated Optoelectronics, College of Electronic Science and Engineering, Jilin University, \\ 2699 Qianjin Street, Changchun 130012, China \\ ${ }^{b}$ State Key Laboratory of Supramolecular Structure and Materials, College of Chemistry, Changchun 130012, P. R. \\ China
}

\section{Synthesis of Au arrow-head nanorod}

Materials: Hexadecyl trimethyl ammonium bromide (CTAB, 99.0\%), sodium borohydride $\left(\mathrm{NaBH}_{4}, 98.0 \%\right)$, silver nitrate $\left(\mathrm{AgNO}_{3}, 99.0 \%\right)$, chloroauric acid $\left(\mathrm{HAuCl}_{4}, 99.99 \%\right)$ and $\mathrm{L}$-ascorbic acid (AA, 99.0\%) were purchased from Sigma Aldrich. Sodium oleate (NaOL, $97.0 \%)$ was purchased from TCI. Chloroform $\left(\mathrm{CHCl}_{3}, 98.0 \%\right)$ was provided by Beijing Chemical Works. Tetrahydrofuran (THF, 99.99\%) was supplied by MERCK. Thiol-terminated polystyrene (PS-SH, $\left.M_{\mathrm{n}}=12,000, M_{\mathrm{w}} / M_{\mathrm{n}}=1.09\right)$ was procured from Polymer Source Inc. Deionized water (18.2 M $\left.\mathbf{2}\right)$ was used in all the experiments.

Synthesis of Gold Long Nanorods (LNRs) and Arrow-head NRs: Gold nanorods (NRs) were synthesized by following the seed-mediated growth method developed by Nikoobakht and El-Sayed. ${ }^{[1]}$ Seed nanoparticles were prepared by mixing HAuCl4 $(0.167 \mathrm{~mL}, 15 \mathrm{mM})$ with an aqueous solution of CTAB $(9.833 \mathrm{~mL}, 0.1 \mathrm{M})$ and adding fresh-prepared $\mathrm{NaBH}_{4}$ solution $(600 \mu \mathrm{L}, 10 \mathrm{mM})$ kept in ice-cold water.

To prepare the growth solution, $0.18 \mathrm{~g}(0.047 \mathrm{M}$ in the final growth solution) of CTAB and $0.02468 \mathrm{~g}(7.65 \mathrm{mM}$ in the final growth solution) of $\mathrm{NaOL}$ were dissolved in $5 \mathrm{~mL}$ of deionized water at $40^{\circ} \mathrm{C}$. Then aqueous solution of $\mathrm{AgNO}_{3}$ $\left(480 \mu \mathrm{L}, 4.0 \mathrm{mM}\right.$ ) was added. The mixture was kept undisturbed at $30^{\circ} \mathrm{C}$ for $15 \mathrm{~min}$ after which aqueous solution of $\mathrm{HAuCl}_{4}(335 \mu \mathrm{L}, 15 \mathrm{mM})$ and $4.665 \mathrm{~mL}$ deionized water were added. The solution became colorless after stirred for 90 min. A concentrated $\mathrm{HCl}$ solution ( 37 wt. $\%$ in water, $84 \mu \mathrm{L}$ ) was then introduced to adjust the pH. After another 15 min of slow stirring, an aqueous solution of AA $(25 \mu \mathrm{L}, 0.064 \mathrm{M})$ was added and the solution was vigorously stirred for $30 \mathrm{~s}$. Finally, $4.0 \mu \mathrm{L}$ of seed solution was injected into the growth solution, which was incubated in a water bath at $30{ }^{\circ} \mathrm{C}$ for 12 hours.

The arrow-head NRs were synthesized following the procedure developed by Xiang et al. ${ }^{[2]}$ Briefly, $0.4 \mathrm{~mL}$ of the 
solution of NRs synthesized as described above was centrifuged once at $8000 \mathrm{rpm}$ for 20 min, and then mixed with aqueous solutions of CTAB $(0.5 \mathrm{~mL}, 0.20 \mathrm{M}), \mathrm{HAuCl}_{4}(16 \mu \mathrm{L}, 15 \mathrm{mM}$ solution $), \mathrm{AgNO}_{3}(60 \mu \mathrm{L}, 4.0 \mathrm{mM})$, and ascorbic acid $(30 \mu \mathrm{L}, 0.788 \mathrm{M})$. The mixture was diluted with deionized water to a finial volume of $3.0 \mathrm{~mL}$ and incubated in a water bath at $30^{\circ} \mathrm{C}$ for 12 hours.

Ligand Exchange of LNRs: For ligand exchange of CTAB, $1.0 \mathrm{mg}$ of PS-SH was dissolved in $1.0 \mathrm{~mL}$ of THF. The concentrated LNRs were rapidly injected into the solution of THF described above. The mixture was incubated for at least 24 hours. The modified LNRs were washed with $\mathrm{CHCl}_{3}$ solution of PS-SH $(1.0 \mathrm{mg} / \mathrm{mL})$ three times to remove CTAB. Furthermore, the NRs were washed with $\mathrm{CHCl}_{3}$ several times to remove the free PS-SH.

Ligand exchange of Arrow-head NRs: For ligand exchange of CTAB, 1.0 mg of PS-SH was dissolved in $1.0 \mathrm{~mL}$ of THF. The solution was added drop-wise into the concentrated solution of LNRs. The mixture was incubated for at least 24 hours and then centrifuged several times. The modified LNRs were washed 5 times with THF. After each centrifugation $(\mathrm{RCF}=4821)$ step, the supernatant was removed and the precipitated PS-tethered LNRs were re-dispersed in THF.
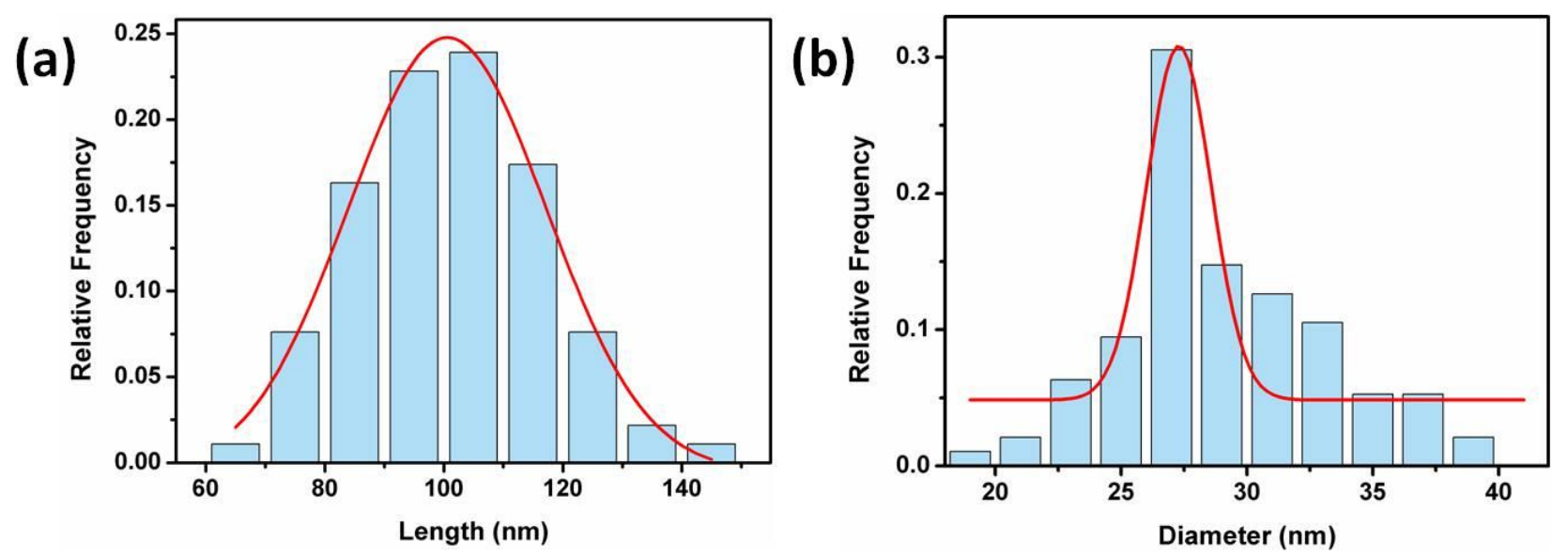

Figure S1. The histogram of (a) Au AHNRs length and (b) Au AHNRs diameter. 


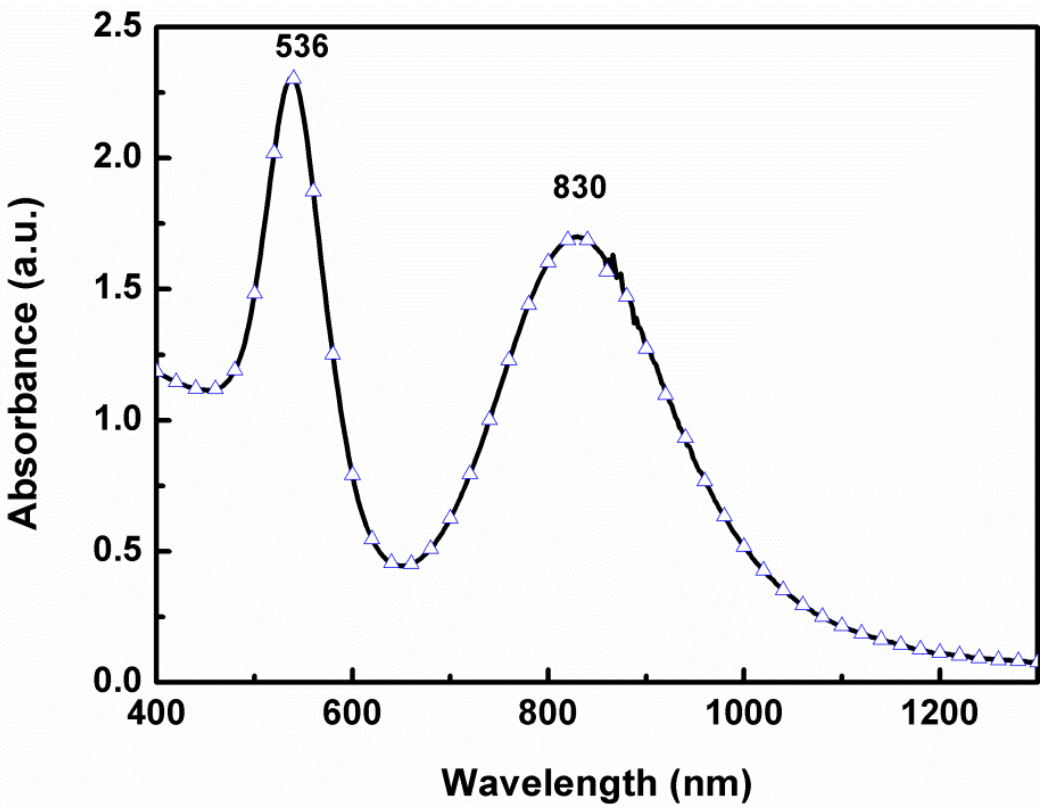

Figure S2. Absorption spectrum of Au AHNRs solution. 


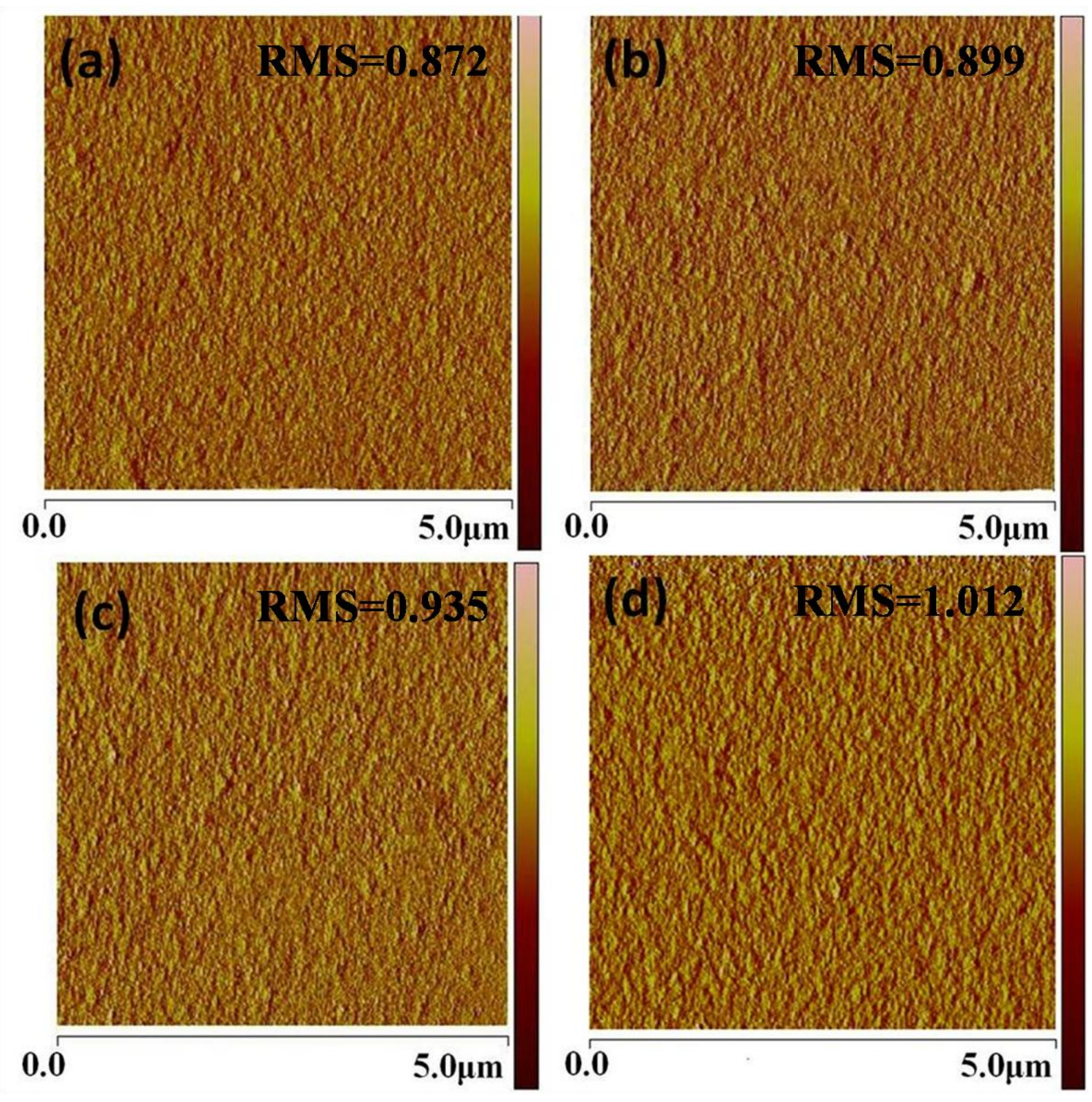

Figure S3. AFM topography of the surface of active films doping (a) without, with (b) $0.5 \mathrm{wt} \%$, (c) $1.0 \mathrm{wt} \%$, (d) $1.5 \mathrm{wt} \%$ Au AHNRs. 


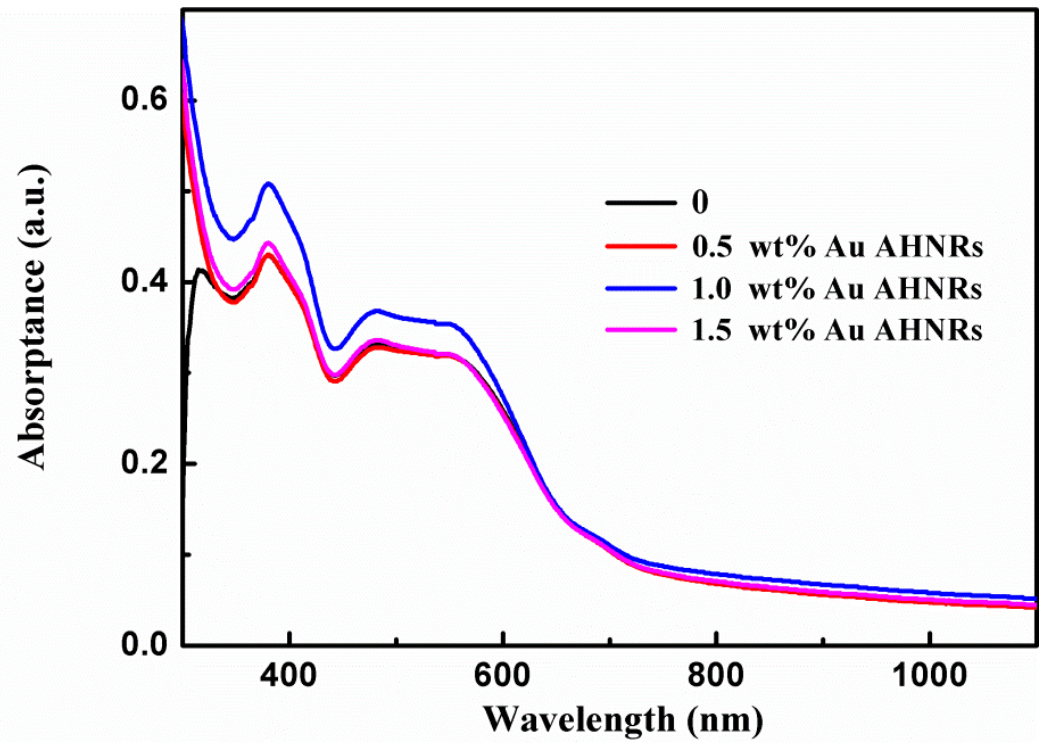

Figure S4. Absorption spectra of active layer doping with different amounts of Au AHNR.

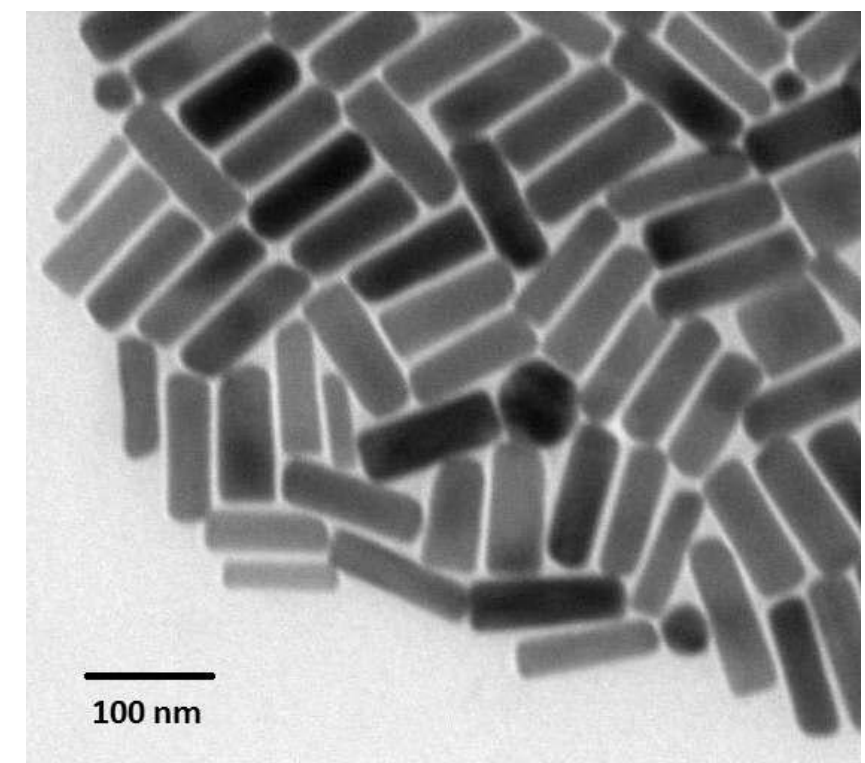

Figure S5. TEM image of Au NRs. 


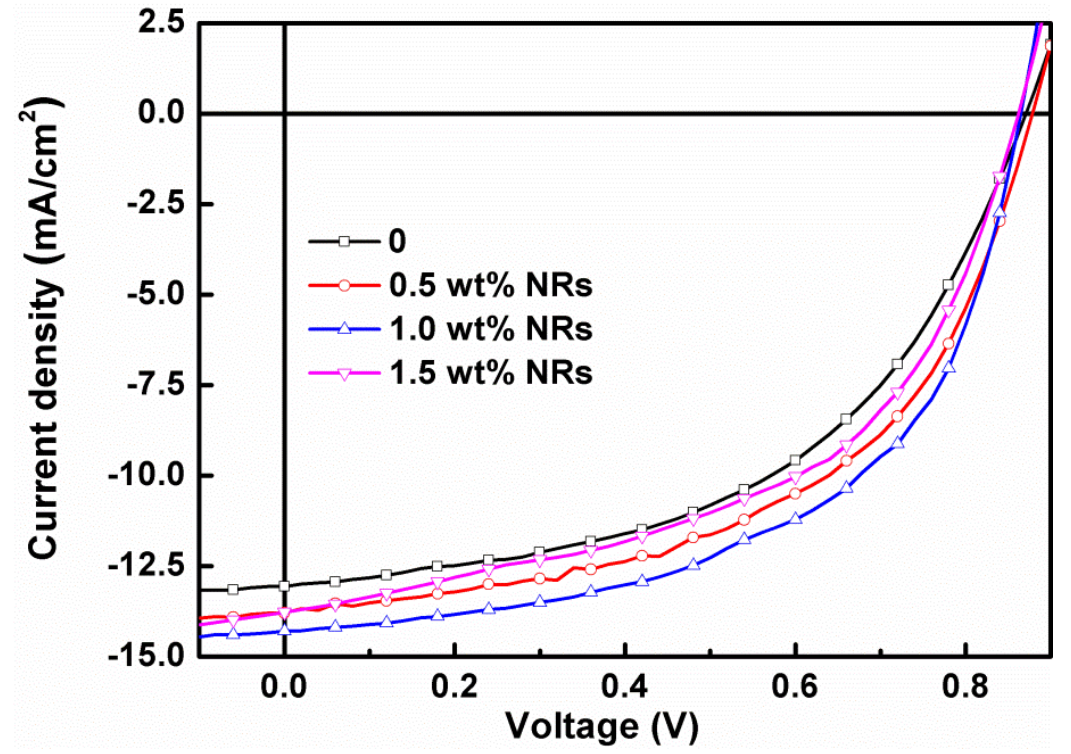

Figure S6. J-V characteristics of devices doping with different amounts of Au NRs.

Table S1. Device performance, including open-circuit voltage $\left(V_{o c}\right)$, short-circuit current density $\left(J_{s c}\right)$, fill factor $(\mathrm{FF})$, and power conversion efficiency (PCE) dependent on concentrations of Au NRs.

\begin{tabular}{ccccc}
\hline Doping amount $(\mathrm{wt} \%)$ & $V_{o c}(\mathrm{~V})$ & $J_{s c}\left(\mathrm{~mA} \mathrm{~cm}^{-2}\right)$ & FF $(\%)$ & PCE $(\%)$ \\
\hline 0 & 0.87 & 13.06 & 50.61 & 5.75 \\
1.0 & 0.88 & 13.79 & 52.66 & 6.39 \\
1.5 & 0.87 & 14.29 & 55.02 & 6.84 \\
2.0 & 0.86 & 13.77 & 51.60 & 6.11 \\
\hline
\end{tabular}

(1) Nikoobakht, B.; El-Sayed, M. A. Preparation and Growth Mechanism of Gold Nanorods (NRs) Using Seed-mediated Growth Method. Chem. Mater. 2003, 15, 1957-1962.

(2) Xiang, Y. J.; Wu, X. C.; Liu , D. F.; Feng, L. L.; Zhang, K.; Chu, W. G.; Zhou, W. Y.; Xie, S. S. Tuning the Morphology of Gold Nanocrystals by Switching the Growth of $\{110\}$ Facets from Restriction to Preference. J. Phys. Chem. C. 2008, 112, $3203-3208$. 